\title{
In-sole plantar pressure device with optimization measurement techniques
}

\author{
O. Hussein ${ }^{1}$, W.Z. Wan Hasan ${ }^{2}$, A. Che Soh ${ }^{3}$, H. Jafaar ${ }^{4}$, H.R. Ramli ${ }^{5}$, S.P. Ang ${ }^{6}$, \\ Zainidi Haji Abdul Hamid \\ ${ }^{1}$ Automated Manufacturing Department, Al-Khawarizmi College of Engineering, University of Baghdad, Iraq \\ ${ }^{2,3,4,5}$ Electrical and Electronics Department, Faculty of Engineering, Universiti Putra Malaysia, Malaysia \\ ${ }^{2}$ Advanced Institute Technology (ITMA), Universiti Putra Malaysia Selangor, Malaysia \\ ${ }^{6,7}$ Electrical and Electronics Engineering, Faculty of Engineering, University Technology Brunei, Brunei
}

\begin{tabular}{l} 
Article Info \\
\hline Article history: \\
Received Apr 12, 2019 \\
Revised Jun 14, 2019 \\
Accepted Jun 28, 2019 \\
\hline
\end{tabular}

\section{Keywords:}

Insole device

Plantar pressure

Underfoot pressure

\begin{abstract}
Doctors and clinicians rely on accurate underfoot pressure data to perform diagnosis of foot diseases. In sole pressure measurement systems are designed to provide such data but its implementation suffers from certain constraints such as the need for a spacer to be placed on the sensor when taking measurements and the need for multiple calibrations due to the fact that the sensor parameters tend to change without it. In this work, we proposed an optimization technique to address these limitations. The results obtained from testing indicate that the proposed device performed measurement of plantar pressure effectively. Also, the calculation of body weight using the proposed optimization technique is improved from $5.07 \%$ to $9.06 \%$. For validation, the results are compared with the measurements from a commercial plantar pressure device (EMED system) as benchmark.
\end{abstract}

Copyright $@ 2020$ Institute of Advanced Engineering and Science. All rights reserved.

\section{Corresponding Author:}

Hafiz Rashidi b Ramli,

Department of Electrical and Computer Engineering,

Faculty of Engineering,

Universiti Putra Malaysia, Serdang, 43400 Selangor, Malaysia.

Email: hrhr@upm.edu.my

\section{INTRODUCTION}

Plantar pressure measurement systems are often used to obtain useful data regarding the structure of the underfoot base and the distribution of pressure it exerts to the surface plane. These systems allow for the diagnosis and treatement of various problems related to posture and gait but there are inherent limitations within these systems that need to be addressed such as the lack of precision in body weight calculation, self-calibration improvements and suitability of the physical characteristics of the materials used. The work in $[1,2]$ studies the effects of obesity or increasing body weight and the resulting disparities in the plantar pressure distribution patterns. Another study found that increase in the human body weight was a significant factor that contributed to the plantar pressure distribution pattern [3, 4]. This leads to recommendation from researchers that the diagnosis and treatment of foot problems in obese patients should consider the effects of increased body mass on their plantar loading $[5,6]$. The study in $[7,8]$ then found that the relationship between mean/peak plantar pressure and increasing body mass was dependent on the affected plantar area.

These prior works show that current insole systems do not consider pressure range in the measurements of plantar pressure. Thus, there is a need for a method to obtain points that can be used to produce a suitable pressure range in the plantar measurement system, specifically the maximum and minimum pressure values during walking and standing, as related to the body mass. The findings of accurate and reliable underfoot pressure ranges based on incremental body weight is needed as a benchmark or 
reference to be used by other reseachers for comparison. In addition, these ranges also enable the differentiation of subjects with and without foot complications as studied by $[9,10]$.

In this paper, we propose an in-sole based plantar pressure measurement device with optimized techniques. The device is designed to measure the range of underfoot pressure and prove its relation to calculations of total body weight and it is expected that the date it produces could be used as a reference or benchmark for other reseachers. In this study, the ethics approval was granted by the Universiti Putra Malaysia Human Research Ethics Committee for the use of experimental subjects.

\section{RESEARCH METHOD}

\subsection{Sensor Selection}

The force sensor that is selected for use in the design of an in-sole plantar pressure measurement device must possess some essential characteristics:

a) The force sensitivity range should be appropriate

b) The sensor must be small, thin and flexible to ensure the comfort of the wearer

c) The driving circuit of the sensor must be simple enough for the instrument to be portable $[11,12]$.

Thus, the piezoresistive force sensor model A201 ${ }^{\mathrm{TM}}$ from Tek-scan was chosen since it fulfills all the requirements. This sensor was used to measure the underfoot pressure with in-sole applications. It was distributed over the touch area of the foot and was calibrated with the recommended procedure for calibration. For such an in-sole system, the pressure sensor was calibrated for the full range, which means that a 100-lb flexi force pressure sensor A 201 had to be calibrated to measure pressure ranging from 0-4400 KPA $[13,14]$.

\subsection{Sensor Distribution and Calibration}

The monitoring of parameters in in-sole systems is becoming a major factor in several fields of scientific research as it may provide useful data on the prevention and treatment of various health conditions, as well as the planning for physical therapy and rehabilitation exercise programs. The parameters for the insole plantar pressure system are set according to the number of sensors and their distribution pattern, which is often determined by the purpose of the in-sole system application. Table 1 summarises the application and number/distribution of sensors in previously developed in-sole systems found in the literature. Since each system has a different aim/application, there is no gold standard for the placement of sensors to measure foot pressure accurately. Cost is also an important factor to consider since increasing the number of sensors could result in a more expensive device. Therefore, it is necessary to find the optimal number and placement of sensors for the in-sole plantar pressure device.

Table 1. Sensor Numbers and Distribution with Different Application

\begin{tabular}{|c|c|}
\hline Number of sensor and Distribution & Application \\
\hline $\begin{array}{l}\text { Eight sensors with positions located at the toe, } 1 \text { st metatarsal, } \\
\text { 3rd metatarsal, 5th metatarsal, } 2 \text { positions at the lateral } \\
\text { forefoot, the medial heel, and the lateral heel [14] }\end{array}$ & $\begin{array}{l}\text { Monitoring the balance of the physical body, identifying the } \\
\text { mechanical dysfunction path, evaluating treatments, and improving } \\
\text { sport skills performance }\end{array}$ \\
\hline $\begin{array}{l}6 \text { units of insole pressure sensors, with three units placed in } \\
\text { the heel area and three units in the metatarsal area [15] }\end{array}$ & Analyse the COP of the body \\
\hline Eight sensors [16] & $\begin{array}{l}\text { Dynamic movements in real time, and are used for clinical gait } \\
\text { analysis }\end{array}$ \\
\hline Eight sensors divided into five positions [17] & Detect a fall and classify the direction of a serious backward fall \\
\hline Five sensors located on the insole [18] & $\begin{array}{l}\text { Estimate the foot load with reasonable accuracy, reduce the cost of } \\
\text { the system and monitor the plantar pressure for daily activity exercise } \\
\text { stress assessments }\end{array}$ \\
\hline $\begin{array}{l}\text { Eight sensors for the in-shoe derived from natural rubber } \\
\text { (Hevea brasiliensis) and equipped with a pressure control [19] }\end{array}$ & $\begin{array}{l}\text { Customised for people who have a diabetic foot with neoformation of } \\
\text { tissues }\end{array}$ \\
\hline
\end{tabular}

The proposed in-sole plantar pressure device (IPPD) system, which was designed to measure underfoot pressure ranges, is illustrated in Figure 1. The sensors were distributed for 15 positions, as shown in Figure 1(a), which are namely (1) back heel, (2) inside of the heel, (3) lateral heel, (4 \& 5) plantar middle, (6 to 10$) 1$ st to 5 th metatarsal head, (11 to 15$) 1$ st to 5 th toe [11]. 
(b) Sensor driving circuit

(a)

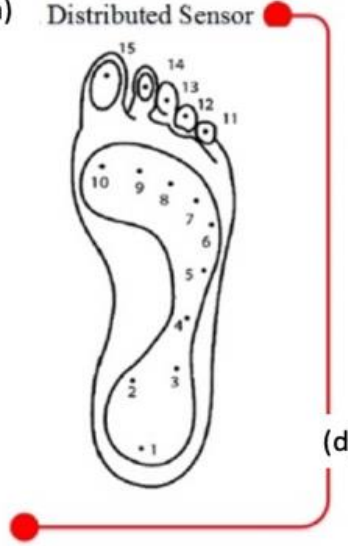

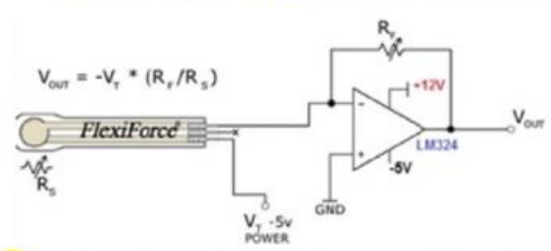

(c) Optimization measurements techniques

Sensor Calibration with range consideration

Set the physical characteristics of sapcer on the sensor

Self-Calibration Procedure

d) Underfoot pressure ranges

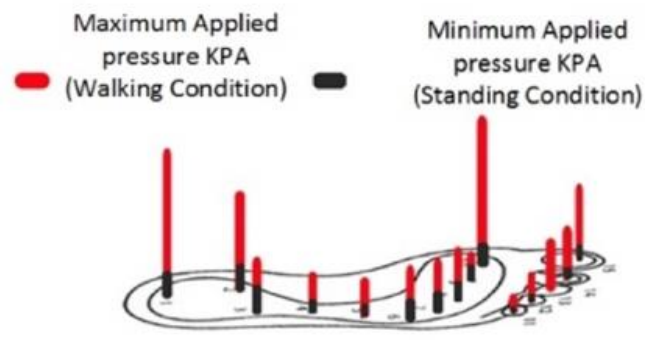

Figure 1. Diagram of proposed insole system (a) Sensor distribution (b) Sensor driving circuit, (c) Optimization measurement techniques (d) Underfoot pressure ranges

When there is no pressure being applied, the Flexi force pressure sensor does not produce any output since due to an infinite resistance value. From the detailed specifications of the sensor, it was found that without any load, the amount of resistance in the sensor is at a minimum of $5 \mathrm{M} \Omega$. As the load applied increases, the sensor resistance value would decrease. An accompanying electrical circuit with an operational amplifier (Figure 1(b)), is needed to produce an output voltage that linearly correlate with the force applied on the sensor. In order to ensure that the voltage output is equal to the sensor output, the sensor is calibrated to have the same value as the total feedback resistance. The sensor output voltage is given by the equation:

$$
V_{o}=V_{\text {in }} \frac{R f}{R s}
$$

The Flexi force pressure sensor from Tek-scan company requires calibration to reduce errors in the pressure measurements [20-22]. It was essential to condition the Flexi force pressure sensor before the calibration and testing to achieve accurate results. Unlike previous in-sole systems, the sensors for the proposed IPPD were calibrated for specific values. These specific values represent the maximum force that was applied to each point under the foot for the maximum sample weight. The calibration procedure can be represented by a Simulink circuit as shown in Figure 2. 


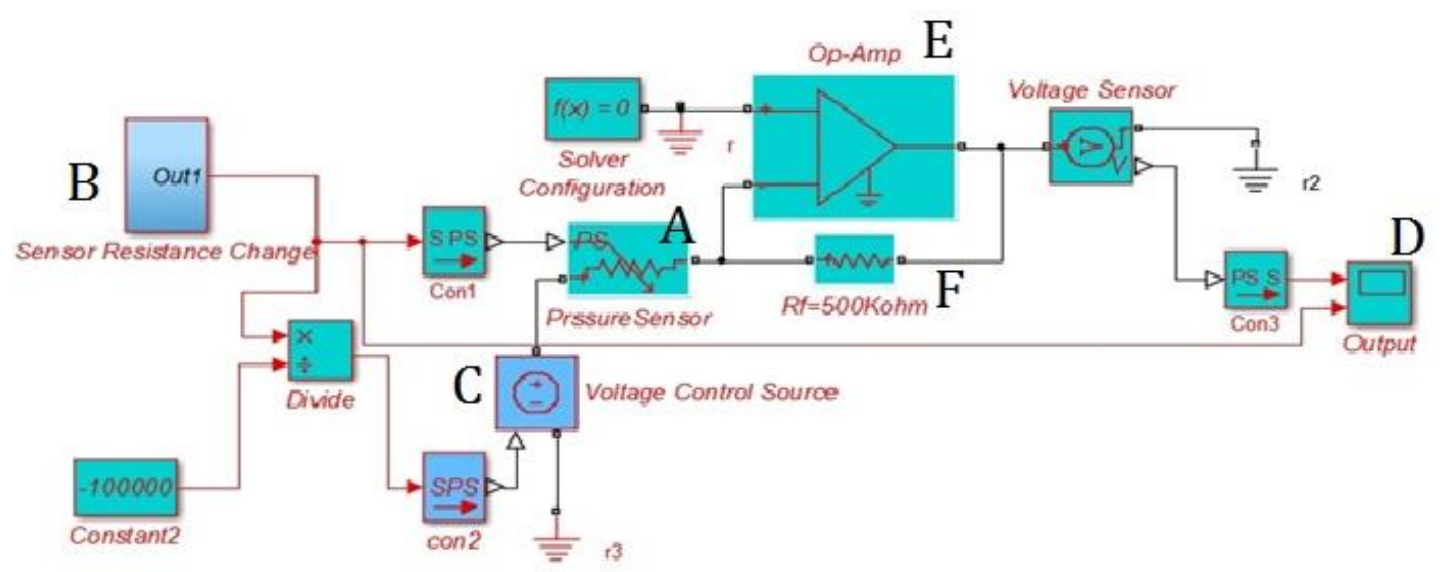

Figure 2. MATLAB simulink circuit representing the calibration procedure

Whare:

A: Pressure sensor with adjustable resistance

B: Variation in sensor parameters after certain period of time

$\mathrm{C}$ : Input voltage controller which relates to sensor parameter changes

D: Sensor output voltage

E: Operational amplifier circuit driving the sensor

F: Feedback resistance.

Once the calibration is performed, future users are advised to repeat the calibration process after a specific amount of time. The calibration procedure is required to analyse the linearity of the applied force with with output voltage produced by the sensor. Figure 3 shows the design of the proposed IPPD and the driving circuits for the sensors.

An important factor that had to be considered in the implementation of the in-sole system was determining the parameters of the spacer to be placed on the effective area of the sensor. This spacer was recommended by the manufacturing company to evenly distribute the pressure applied to the sensor [20]. Preliminary tests and also previous work [23, 24] have showed that without the use of a spacer on the effective area, a higher measurement error will be produced compared to when a spacer is used. However, the suitable material and dimensions of the spacer to obtain accurate measurements were not specified. Rigid materials, such as plastic and rubber were considered as possible candidates for the spacer material. The thickness of this material should be suitable and unobtrusive for the user. Experiments were carried out to examine which material is suitable and able to produce minimum measurement error. A Universal Testing Machine (UTM) was used to apply a force of $10 \mathrm{~kg}(98 \mathrm{~N})$, as shown in Figure 4.

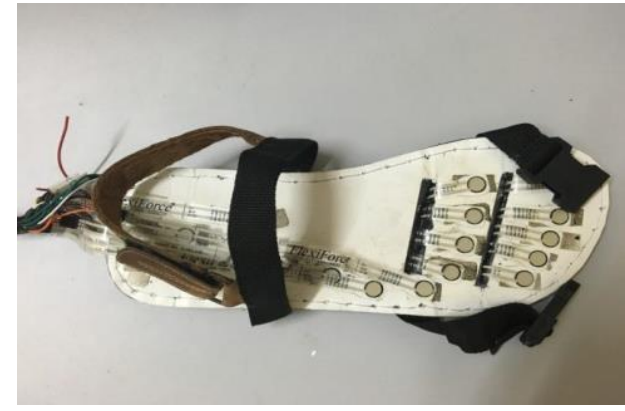

(a)

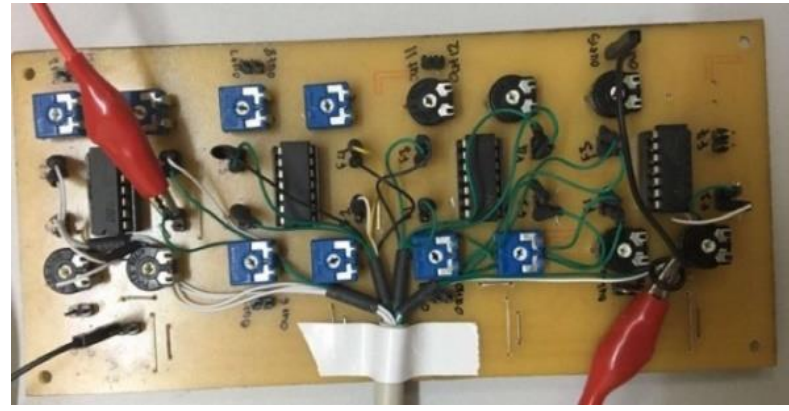

(b)

Figure 3. (a) The proposed IPPD and (b) driving circuits 


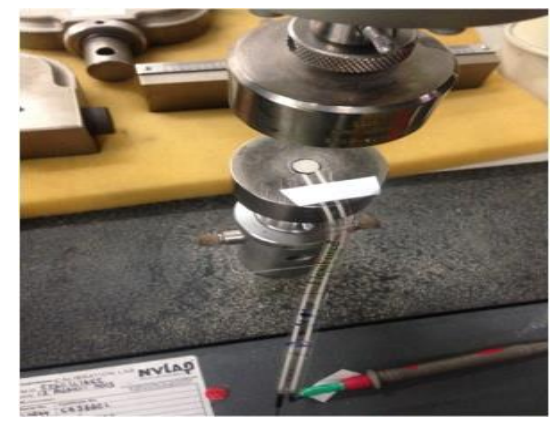

Figure 4. Universal testing machine with plastic spacer with flexi force pressure sensor

\subsection{Underfoot Pressure Measurement Methodology using Proposed IPPD}

The measurement of underfoot pressure using the IPPD plays a role in the understanding and detection of certain problems in relation to foot complications. The proposed IPPD was designed to measure the underfoot pressure for 15 positions that are considered as important positions for supporting the body weight $[25,26]$. Following the application of the optimization measurement techniques with the proposed IPPD, this section explains the methodology for the measurement of the underfoot pressure to obtain the data regarding the minimum and maximum pressure from each point under the foot. The underfoot pressure measurement methodology involved several steps. Firstly, the IPPD was set up and the participants were requested to wear the proposed IPPD. Next, the peak pressure (maximum applied pressure) was measured by asking the participants to walk for two steps at a normal walking speed using the proposed IPPD. Then, the touch pressure (minimum applied pressure) was measured during the standing condition. Finally, the body weight was calculated using (1):

$$
\left\{\begin{array}{l}
\text { Sample Body Weight }=\sum_{n=1}^{n=15} \frac{P_{n}}{A} * \frac{1}{\text { Effective area } \%} * 2 \\
\text { Sample Body Weight }=\sum_{n=1}^{n=15} W_{n} \frac{1}{\text { Effective area } \%} * 2 \\
\text { Sample Body Weight }=\sum_{\mathrm{n}=1}^{\mathrm{n}=15} \frac{\mathrm{X}_{\mathrm{n}}}{5 \mathrm{v}} V_{\mathrm{n}} * \frac{1}{\text { Effective area } \%} * 2
\end{array}\right.
$$

$\mathrm{n}$ : Number of sensors

$\mathrm{P}$ : Pressure measured during standing condition in (KPA)

$\mathrm{W}$ : Extracted weight of each sensor $(\mathrm{kg})$

$\mathrm{V}$ : Output voltage from each sensor under the foot $(\mathrm{V})$

$\mathrm{X}$ : The particular value of the weight range in which the sensor was calibrated based on its position $(\mathrm{Kg})$

A : Factor $=98$, which converts $1 \mathrm{~kg} / \mathrm{cm}^{2}$ to KPA.

Effective area: The sensors covered around $8.6 \%$ of the whole area of the foot.

After extracting the underfoot pressure ranges for the different samples, the body weight of each sample was also calculated. Finally, the minimum and maximum pressures under the foot in relation to the increasing body weight were determined. After that, the participants were requested to use the current in-sole system again and the novel EMED system for the measurement of touch pressure and the calculation of the body weight.

\section{RESULTS AND ANALYSIS}

\subsection{Spacer Material and Dimensions Test}

The experiment for calculating the standard weight to be applied using a UTM was explained in methodology section. After the sensors had been calibrated for a specific value, and the effective area of the distributed sensors had been calculated, a verification process was carried out using a spacer. Table 2 shows the percentage of error between the applied weight using the UTM and the calculated weight using the distributed pressure sensors with three different conditions (using a plastic spacer with a thickness of 0.55 $\mathrm{mm}$, using a rubber spacer with a thickness of $0.55 \mathrm{~mm}$, and without using a spacer). 
Table 2. Weight Calculations using Pressure Sensors with and Without Applying A Spacer

\begin{tabular}{|c|c|c|c|}
\hline & $\begin{array}{l}\text { Measured force using pressure } \\
\text { sensor with a plastic spacer }(\mathrm{N})\end{array}$ & $\begin{array}{l}\text { Measured force using pressure } \\
\text { sensor with a rubber spacer }(\mathrm{N})\end{array}$ & $\begin{array}{l}\text { Measured force using pressure } \\
\text { sensor without a spacer }(\mathrm{N})\end{array}$ \\
\hline Calculated force, $\mathrm{N}$ & 94.4321185 & 91.559518 & $85.2659276 \mathrm{~N}$ \\
\hline Percentage of error & $3.12 \%$ & $6.57 \%$ & $12.4 \%$ \\
\hline
\end{tabular}

The error of measurement between the applied weight using the UTM and the measured weight obtained using the distributed sensor measurements without using a spacer was $12.4 \%$. Meanwhile, the measurement error between the applied weight and the measured weight reached $3.12 \%$ when a plastic spacer was used, and $6.57 \%$ when a rubber spacer was used. It was concluded that, during experiments, it is necessary to place the spacer made of plastic material, with a thickness of $0.55 \mathrm{~mm}$, onto the sensors to obtain precise and accurate measurements.

\subsection{Analysing Measurement Precision with Applied Calibration Technique}

As mentioned in the introduction, there is an inherent challenge with the use of the Flexiforce pressure sensor, where the sensor parameters would change after a period of time following the calibration. In this research, the change in sensor parameters was analysed by studying the variance in measurements after a period of time following the calibration. Table 3 shows the changes in the sensor parameters in terms of the relationship between the applied force and the sensor output voltage after a period of time following the calibration. The relationship between the applied force and the output voltage was determined from Figure 5, which showed that the characteristics curve of the sensor after a period of time following the calibration was affected only by the sensor output, while the relationship between the applied force and the output voltage remained linear.

Table 3. Sensor Output vs. Applied Force After a Period of Time Following the Calibration

\begin{tabular}{cccc}
\hline Applied Force (N) & $\begin{array}{c}\text { Output Voltage (V) from } \\
\text { sensor after calibration }\end{array}$ & $\begin{array}{c}\text { Output Voltage (V) from sensor } \\
\text { after one day of calibration }\end{array}$ & $\begin{array}{c}\text { Output Voltage (V) from sensor } \\
\text { after two days of calibration }\end{array}$ \\
\hline 111 & 5.00 & 3.8 & 3.3 \\
99 & 4.50 & 3.471 & 2.9 \\
89.6 & 4.01 & 3.115 & 2.6 \\
78.4 & 3.50 & 2.759 & 2.3 \\
67.2 & 2.90 & 2.3763 & 1.99 \\
56 & 2.42 & 1.958 & 1.67 \\
44.8 & 1.86 & 1.4863 & 1.32 \\
33.6 & 1.44 & 1.068 & 0.98 \\
22.4 & 0.93 & 0.5963 & 0.6 \\
11.2 & 0.50 & 0.178 & 0.12 \\
\hline
\end{tabular}

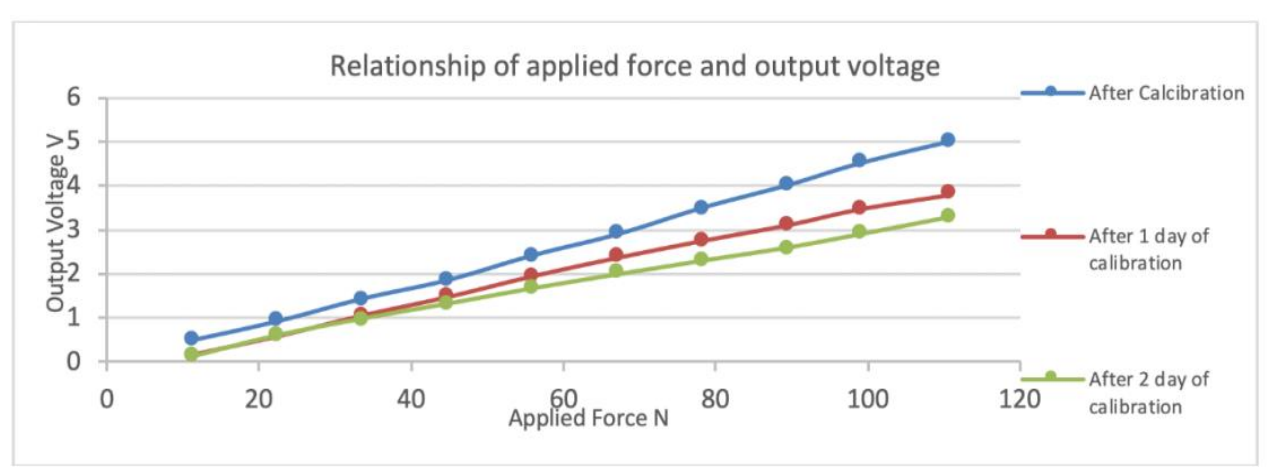

Figure 5. Relationship between the applied force and output voltage after a period of calibration

The simulation results of the calibration procedure, represented by the MATLAB model in methodology section, are shown in Figure 6. Based on the calculated values, it was concluded that the calibration procedure for the Flexi force pressure sensor needs to be performed routinely to maintain the same low measurement error. The time required to apply the calibration procedure was determined by applying the procedure on the sensor and tracing the relationship between the applied force and the output 
voltage. Figure 7 shows the sensor parameters after applying the calibration and after one hour of calibration. This shows that the sensor parameters remained the same after one hour of application of the self-calibration technique. Thus, it is recommended that the self-calibration be repeated after one hour to maintain the same measurement from the sensor.

There was an improvement in the calculated body weight using the insole system after the sensor had been calibrated for the maximum applied pressure (range considerations). As shown in Table 4, the percentage of error between the actual body weight and the calculated body weight using the IPPD system with the sensor calibrated for range considerations amounted to $7.10 \%$. This is lower than the percentage of error when the sensors had been calibrated without range considerations which amounted to $8.79 \%$. This variance in terms of the calculated body weight highlights the importance of calibration with range considerations to ensure more precise and accurate measurements can be obtained.

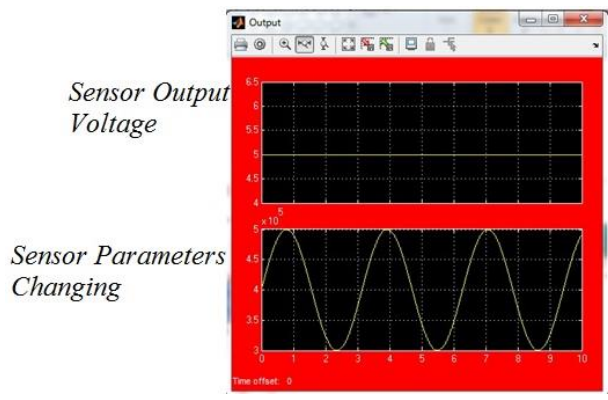

Figure 6. Calibration output

Table 4. Body Weight Calculation using Insole System with Two Considerations of Sensor Calibration

\begin{tabular}{|c|c|c|c|c|}
\hline $\begin{array}{l}\text { Body weight }(\mathrm{kg}) \\
\text { using weighing scale }\end{array}$ & $\begin{array}{c}\text { Insole system sensors calibrated } \\
\text { with range considerations }\end{array}$ & $\begin{array}{c}\text { Percentage } \\
\text { of error }\end{array}$ & $\begin{array}{l}\text { Insole system sensors calibrated } \\
\text { without range considerations }\end{array}$ & $\begin{array}{c}\text { Percentage of } \\
\text { error }\end{array}$ \\
\hline 95 & 87.9 & $7.47 \%$ & 86.5 & $8.95 \%$ \\
\hline 87 & 80.5 & $7.47 \%$ & 79.2 & $8.97 \%$ \\
\hline 83 & 77.5 & $6.63 \%$ & 75.8 & $8.67 \%$ \\
\hline 75 & 70.1 & $6.53 \%$ & 69.5 & $7.33 \%$ \\
\hline 63 & 58.8 & $6.67 \%$ & 57.85 & $8.17 \%$ \\
\hline 60 & 55.8 & $7.00 \%$ & 55.1 & $8.17 \%$ \\
\hline 58 & 53.9 & $7.07 \%$ & 53.1 & $8.45 \%$ \\
\hline 55 & 51.1 & $7.09 \%$ & 49.8 & $9.45 \%$ \\
\hline \multicolumn{2}{|c|}{ Percentage of error } & $7.10 \%$ & & $8.79 \%$ \\
\hline
\end{tabular}

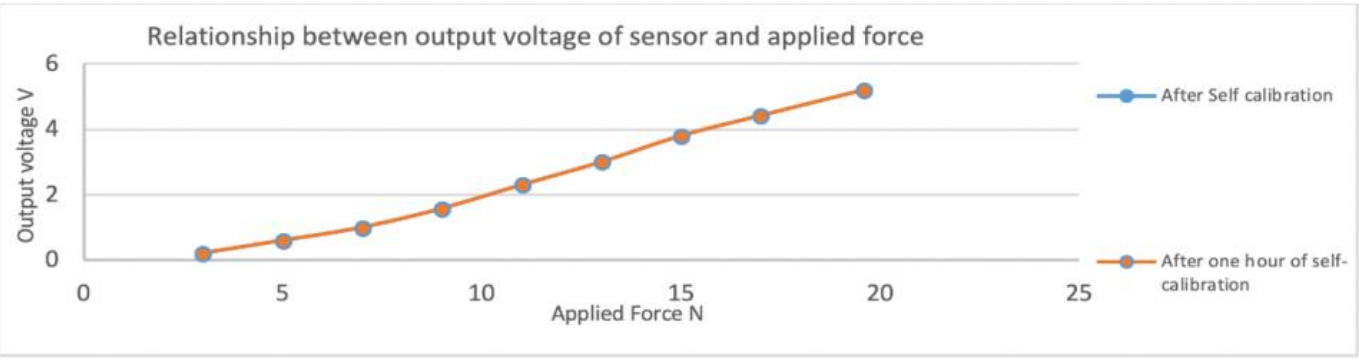

Figure 7. Relationship between output voltage of sensor and applied force after one hour of calibration

\subsection{Underfoot Pressure Measurements using Proposed IPPD}

The underfoot pressure range measurements obtained with the implementation of the IPPD are presented in this section. The relationship between the maximum and minimum applied pressure by way of increasing body weight for healthy subjects (i.e. subjects without any foot complications) was represented by 
a linear correlation with increasing body weight, as shown in Figures 8 and 9. The former showing the results for male subjects and the latter for female subjects. The procedure for calculating the body weight was applied, and the result was compared with a standard insole system (insole system designed without optimization techniques) and another commercial device (novel EMED system). The novel EMED system is regarded as an accurate electronic system for recording and evaluating the underfoot pressure distribution in static and dynamic conditions [20].
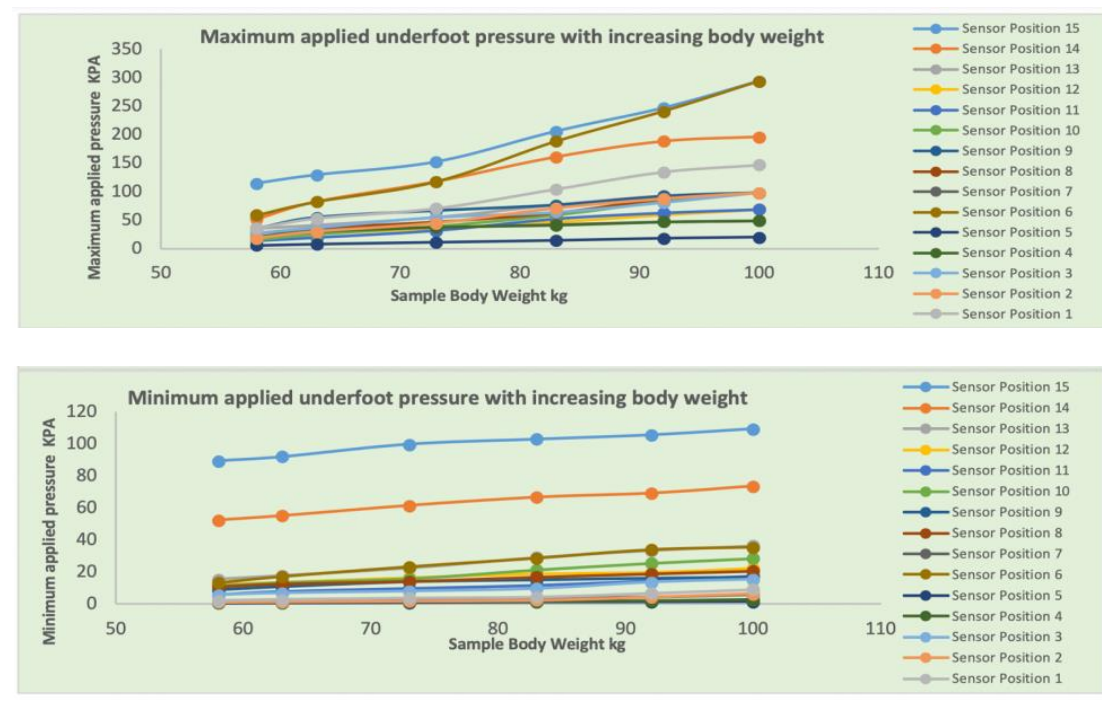

Figure 8. Maximum (top) and minimum (below) applied pressure with increasing body weight for male group
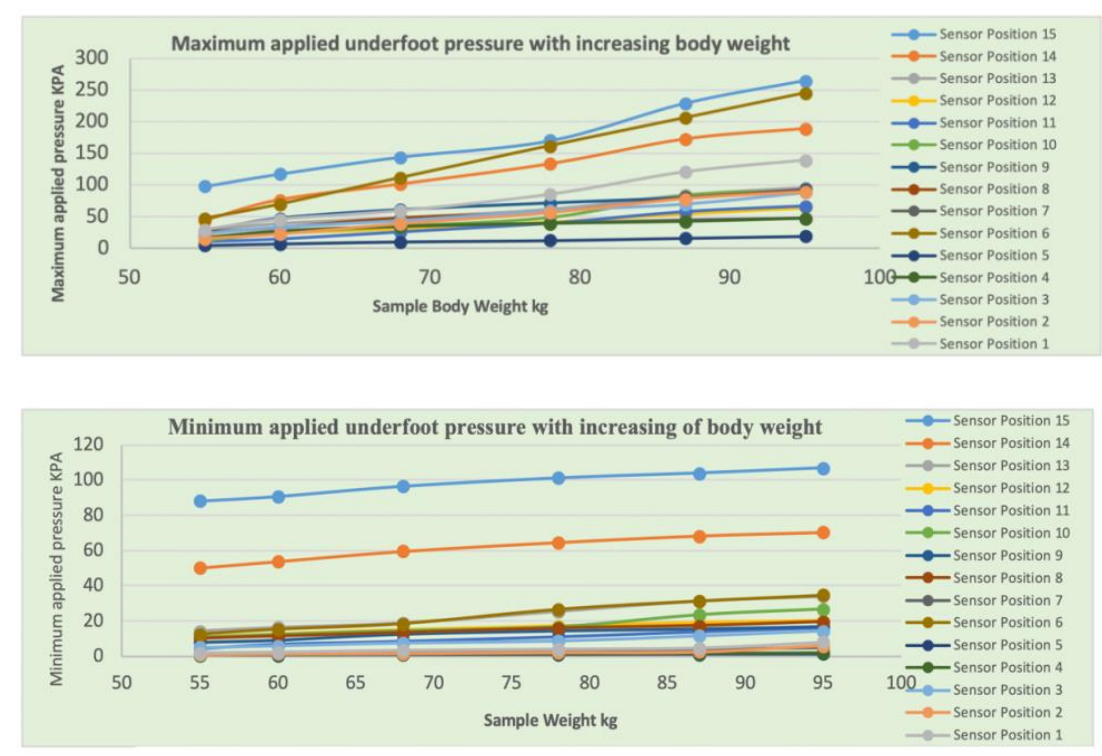

Figure 9. Maximum (top) and minimum (bottom) applied pressure with increasing body weight for female group

Table 5 shows the comparison between the novel EMED system, the current insole system and the IPPD in terms of the body weight calculation and the percentage of error between the real and measured values. It was observed that the estimated body weight from the IPPD system with optimization techniques had a similar percentage of error to the estimated body weight from the EMED system, with a difference of only $0.14 \%$. 
Table 5. Comparison between the Novel EMED System, the Current Insole System and the IPPD in Terms of the Body Weight Calculation

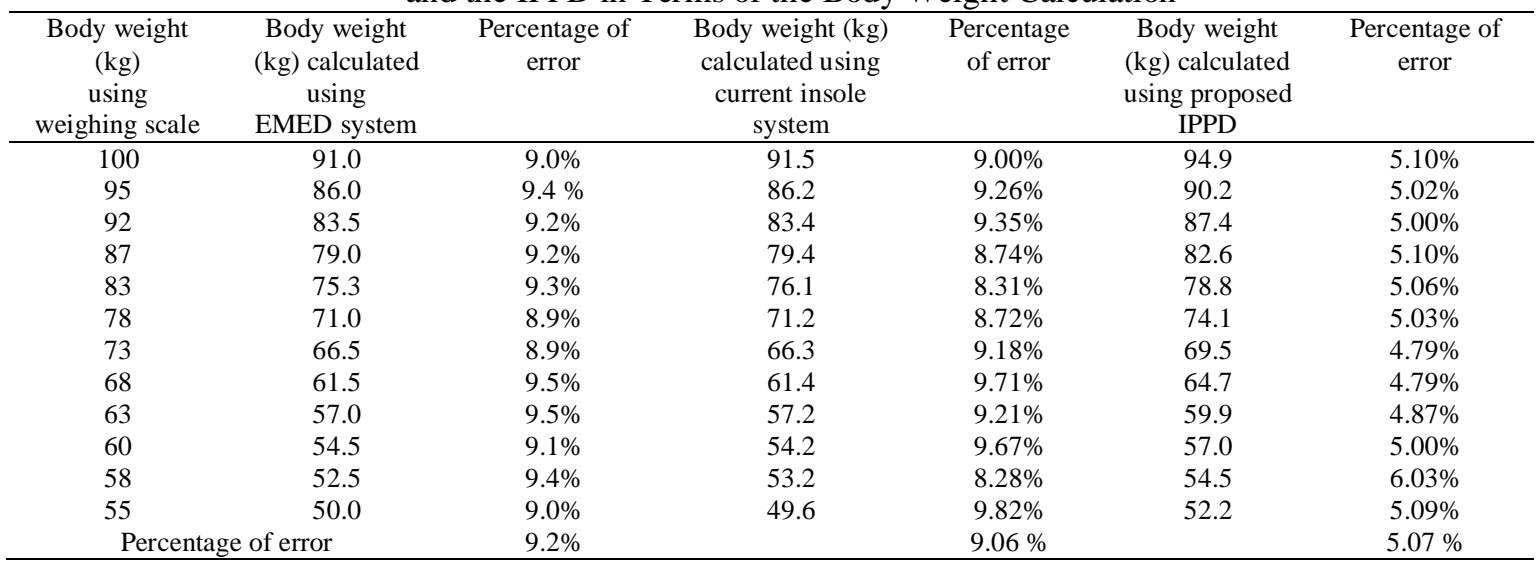

\section{CONCLUSION}

Underfoot pressure ranges were measured using the proposed IPPD with the applied optimization techniques and these experiments led to several findings. Firstly, it was shown that there was an improvement in the calculation of the weight following the use of a spacer onto the sensors during the experiments. The experiments showed that a spacer made of plastic, with a thickness of $0.55 \mathrm{~mm}$, can help to produce measurements with less error than when a spacer is not used. Secondly, it was proven that the optimization measurement techniques, especially the calibration of the sensor with range considerations, resulted in an improvement in the pressure measurements. The measurement error percentage improved from $8.79 \%$ (calibrated without range consideration) to $7.10 \%$ (calibrated with range consideration).

Thirdly, the experiments showed that the calibration was useful for maintaining the same measurement error. This is important since the measurement error tends to increase after a period of time. Fourthly, using the IPPD with the optimization techniques to estimate body weight, it was found that the percentage of error was $5.07 \%$ from the actual weight. This is a significant improvement since the percentage of error reached $9.2 \%$ using the novel EMED system and $9.06 \%$ using the current insole system without the mentioned optimization techniques.

It is hoped that the findings of this research will benefit society based on the fact that plantar pressure measurements could potentially play an important role as key health indicators. In addition, this research will contribute to the industrial sector by providing an IPPD with optimization measurement techniques that can produce precise measurements of underfoot pressure, in terms of estimating body weight, as compared to existing commercial devices, such as the novel EMED system. Future work should focus on improving the IPPD further either by adding more pressure sensors that are strategically placed or by implementing an algorithm to the system that could predict any occurrence of foot complications based on current underfoot pressure data.

\section{ACKNOWLEDGEMENTS}

The authors would like to thank the Ministry of Education and University Putra Malaysia for providing the project funding under the FRGS scheme (03-02-13-1280FR), (03-02-13-1279FR), PUTRA IPM and IPB schemes (GP-IPM/2013/9401500), (GP-IPB/2014/9440801).

\section{REFERENCES}

[1] A. P. Hills, E. M. Hennig, M. McDonald, and O. Bar-Or, "Plantar pressure differences between obese and nonobese adults: a biomechanical analysis," Int. J. Obes. Relat. Metab. Disord, vol. 25, no. 11, pp. 1674-9, 2001.

[2] M. Birtane and H. Tuna, "The evaluation of plantar pressure distribution in obese and non-obese adults," Clin. Biomech, vol. 19, no. 10, pp. 1055-1059, 2004.

[3] T. E., T. L.F., A. U. R., H. T.P., G. E., and M. L.C., "Static and frequency domain analysis of plantar pressure distribution in obese and non-obese subjects," Journal of Bodywork and Movement Therapies, vol. 10, no. 2. pp. 127-133, 2006.

[4] L. Wafai, A. Zayegh, J. Woulfe, S.M. Aziz and R. Begg, "Identification of Foot Pathologies based on Plantar Pressure Asymmetry," Sensors, vol. 15(8), pp. 20392-20408, 2015. 
[5] P. A. Butterworth, D. M. Urquhart, K. B. Landorf, A. E. Wluka, F. M. Cicuttini, and H. B. Menz, "Foot posture, range of motion and plantar pressure characteristics in obese and non-obese individuals," Gait Posture, vol. 41, no. 2, pp. 465-469, 2015.

[6] S. Mueller, A. Carlshon, J. Mueller, H. Baur and F. Mayer, "Influence of Obesity on Foot Loading Characteristics in Gait for Children aged 1 to 12 years," PLoS One, vol. 11(2), 2016.

[7] J. B. Arnold, R. Causby, and S. Jones, "The impact of increasing body mass on peak and mean plantar pressure in asymptomatic adult subjects during walking," Diabet. Foot Ankle, vol. 1, 2010.

[8] S.S. Zulkifli and W.P.Loh, "A state of the art review of foot pressure," Foot and Ankle Surgery, 2018.

[9] U. Flexi, F. Sensors, and M. Chaskar, "Development of Planter Foot Pressure Distribution System," vol. 108, no. 9, pp. 73-79, 2009.

[10] D.V. Rai and L. Aggarwal, "The Study of Plantar Pressure Distribution in Normal an Pathological Foot," Polish Journal of Medical Physics and Engineering, vol. 12(1), 2006.

[11] C. Zhu, A. Song, and Y. Ma, "A wireless gait measuring instrument based on plantar pressure measuring," in Proceedings - IEEE 2011 10th International Conference on Electronic Measurement and Instruments, ICEMI 2011, 2011, vol. 1, pp. 146-150.

[12] E. Campo, Y. Charlon, and D. Brulin, "Instrumented Insole fpr Weight Measurement of Frail People," Proceedings of the 8th ACM International Conference on PErvasive Technologies Related to Assistive Environments (PETRA 2015), 2015.

[13] J.J. A. Mendes Jr., M.E.M. Viera, M.B. Pires and S.L. Stevan Jr., "Sensor Fusion and Smart Sensor in Sports and Biomedical Applications," Sensors, vol. 16(10), 2016.

[14] U. Manupibul, W. Charoensuk, and P. Kaimuk, "Design and development of SMART insole system for plantar pressure measurement in imbalance human body and heavy activities," in BMEiCON 2014 - 7th Biomedical Engineering International Conference, 2015.

[15] Lin Shu, at al., "In-shoe plantar pressure measurement and analysis system based on fabric pressure sensing array," IEEE Trans. Inf. Technol. Biomed., vol. 14, no. 3, pp. 767-775, 2010

[16] R. Karkokli and K. M. V. McConville, "Design and development of a cost effective plantar pressure distribution analysis system for the dynamically moving feet.," Conf. Proc. IEEE Eng. Med. Biol. Soc., vol. 1, pp. 6008-11, 2006.

[17] T. Yanbo, Q. Huihuan, C. Meng, S. Xin, and X. Yangsheng, "A Real-time intelligent shoe system for fall detection," in Robotics and Biomimetics (ROBIO), 2011 IEEE International Conference on, 2011, pp. 2253-2258.

[18] L. Ren, D. Li, C. Liu, Y. Yang, Y. Qian, S. Yang, F. Pu, and H. Niu, "Design of in-shoe plantar pressure monitoring system for daily activity exercise stress assessment," Biomed. Eng. Informatics (BMEI), 2011 4th Int. Conf., vol. 3, pp. 1367-1370, 2011.

[19] M. D. C. Dos Reis, F. A. Soares, A. F. Da Rocha, J. L. A. Carvalho, and S. S. F. R. Rodrigues, "Insole with pressure control and tissue neoformation induction systems for diabetic foot," in 2010 Annual International Conference of the IEEE Engineering in Medicine and Biology Society, EMBC'10, 2010, pp. 5748-5751.

[20] F. M. and T. S. Pressure Mapping, "Flexiforce pressure sensor," [Online], Available: https://www.tekscan.com /flexiforce-load-force-sensors-and-systems. [Accessed: 01-Jul-2016].

[21] S. Parmar, I. Khodasevych, and O. Troynikov, "Evaluation of Flexible Force Sensors for Pressure Monitoring in Treatment of Chronic Venous Disease," Sensors, vol. 17(8), 2017.

[22] G. Pang, J. Deng, F. Wang, J. Zhang, Z. Pang and G. Yang, "Development of Flexible Robot Skin for Safe and Natural Human-Robot Collaboration," Micromachines, vol. 9(11), 2018.

[23] P.S. Malvade, A.K. Joshi, and S.P. Madhe, "IoT Based Monitoring of Foot Pressure using FSR Sensor," Proceedings of International Conference on Communication and Signal Processing (ICCSP), 2017.

[24] J. Fastier-Woodler, H.P. Phan, T. Dinh, T.K. Nguyen, A. Cameron, A. Ochsner and D.V. Dao, "Novel Low Cost Sensor for Human Bite Force Measurement," Sensors, vol. 16(8), 2016.

[25] O. Hussein, W.Z. Wan Hasan, A. Che Soh. H. Jaafar, H.R. Ramli, S.P. Ang, Zainidi Haji Abdul Hamid, "Development of an In-Sole Plantar Pressure Measurement Device," Proceedings - IEEE 2018 International Conference of Smart Instrumentation, Measurementa and Applications, ICSIMA 2018.

[26] N.A. Malik, Z. Wahid, S.N. Ibrahim, T.S. Gunawan, and S. Khan, "Investigation of lower limb's muscles activity during performance of salat between two age groups," Indonesian Journal of Electrical and Computer science (IJEECS), vol. 14(2), pp. 608-617, 2019.

\section{BIOGRAPHIES OF AUTHORS}

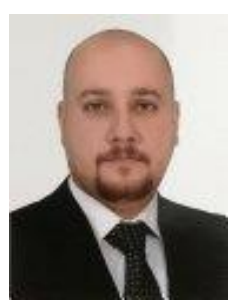

Omar Hussein is currently a lecturer at the Al-Khwarizmi College of Engineering, University of Baghdad in Iraq. He obtained his PhD in 2014 from Universiti Putra Malaysia. His areas of research interest include biomedical engineering, plantar pressure measurement system, diabetes wound prediction and rehabilitation. 

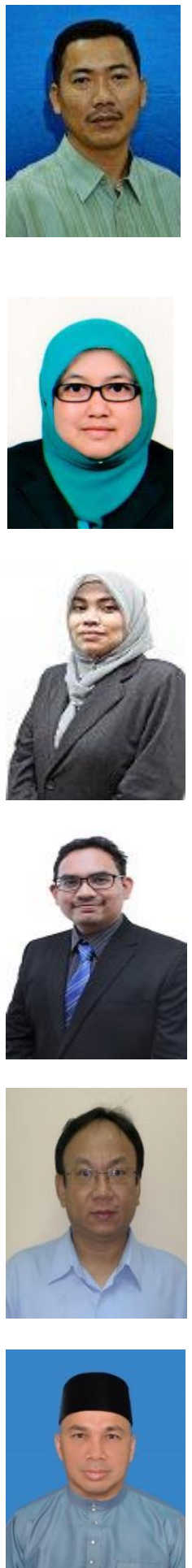

Wan Z. W. Hasan is an Associate Professor at the Electrical and Electronics Engineering, Faculty of Engineering, Universiti Putra Malaysia (UPM). He received the B.Sc. degree in Electronic and Computer from the Universiti Putra Malaysia (UPM) in 1997, and the M.Sc. in Microelectronics from the Universiti Putra Malaysia (UPM) in 2001, and the Ph.D. in Memory Testing from the University Kebangsaan Malaysia (UKM) in 2005. He is a member IEEE member (BEM), IEEE Circuit and System Society (IEICE) and IEEE Electron and Devices (PPAUPM). His areas of specialization are Microelectronics, Sensor Technology, Robotic and Automation, especially in Pressure Sensor for Medical and Robotic and Automation Application, Mobile Robot, utomated Machine and Memory Testing includes Built-in Self-test and Self-diagnose. ORCID: orcid.org/0000-0003-4691-066X

Dr Azura Che Soh is currently an Associate Professor at the Department of Electrical and Electronics Engineering, Faculty of Engineering, Universiti Putra Malaysia. She obtained a B.Eng in Electronic and Computer Engineering from Universiti Putra Malaysia in 1999. In 2002, she received her MSc in Electrical and Electronic Engineering at the same institution. In 2011, she successfully achieved her $\mathrm{PhD}$ in Electrical Engineering from Universiti Teknologi Malaysia. Her research areas include Control System Engineering, Intelligent Control and System Modeling and Simulation.

Dr Haslina Jaafar is currently a senior lecturer at the Department of Electrical and Electronics Engineering, Faculty of Engineering, Universiti Putra Malaysia. She obtained her B.Eng in Electrical, Electronics and Systems Engineering from Universiti Kebangsaan Malaysia in 1999. In 2001, she received her MSc in Microelectronics Engineering at the same institution. In 2014, she successfully achieved her $\mathrm{PhD}$ in Microelectronics Engineering from Universiti Sains Malaysia. Her research areas include Micro-Electro-Mechanical Systems (MEMS) and Microsystems, MEMS Sensor and Actuators and CMOS-MEMS integration.

Dr Hafiz Rashidi Ramli is currently a senior lecturer at the Department of Electrical and Electronics Engineering, Faculty of Engineering, Universiti Putra Malaysia. He received his B.Eng in Electrical and Electronics Engineering and MSc in Control and Automation Engineering at Universiti Putra Malaysia. In 2017, he obtained his PhD from Imperial College in Biomedical Engineering. His area of research includes medical simulation, haptic interfacing, image processing and robotics.

Swee Peng Ang was born in Brunei Darussalam. He received a BEng (Hons) degree in Electronic \& Electrical Engineering in 1995 from University of Glasgow, UK and a MSc in Electrical Power Engineering in 2002 from University of Manchester Institute Science and Technology (UMIST), UK. He graduated with a Ph.D. degree at the University of Manchester, UK in 2010. He is currently a principal lecturer in Electrical and Electronic Enginnering Programme Area, Universiti Teknologi Brunei, Negara Brunei Darussalam. His research interests include transformer modeling, ferroresonance studies in power systems, solar power system and control in power system

Zainidi Haji Abdul Hamid is a Senior Lecturer in Electrical and Electronic Engineering Programme area, Faculty of Engineering, Universiti Teknologi Brunei, Negara Brunei Darussalam. He is currently a programme leader for EEE programme area since 2016 to date. He received a BEng (Hons) in Telecommunication Systems from Anglia Polytechnic University, United Kingdom in 1997, and the MSc in Data Communication Systems from Brunei University, UK in 1998. He pursue his PhD. in Electrical and Electronics Engineering and received MPhil. in 2018 from University of Southampton, UK. His current interests are in the area of nano-materials, photonics and communications. 